\title{
Impact of Smart City Planning and Construction on Community Governance under Dynamic Game
}

\author{
Jie Guo' and Wenhao Ling $\mathbb{D}^{2}$ \\ ${ }^{1}$ Institute of Administration Study, Henan University, Kaifeng, Henan 475004, China \\ ${ }^{2}$ Institute of Local Government and Societal Governance, Henan University, Kaifeng, Henan 475004, China \\ Correspondence should be addressed to Wenhao Ling; lwh@henu.edu.cn
}

Received 15 December 2020; Revised 6 January 2021; Accepted 20 January 2021; Published 30 January 2021

Academic Editor: Wei Wang

Copyright (c) 2021 Jie Guo and Wenhao Ling. This is an open access article distributed under the Creative Commons Attribution License, which permits unrestricted use, distribution, and reproduction in any medium, provided the original work is properly cited.

\begin{abstract}
We present a research on smart city planning and community governance using dynamic game methods, analyze the current status and problems of the current smart community service system, and put forward countermeasures and suggestions based on the global smart community development experience. Through smart city planning and construction, the game model of government governance and information sharing between communities and decision making is obtained, and the two-dimensional replication dynamic system equations of smart city planning and construction agencies and communities are obtained from smart city planning and construction. The evolutionary stability strategy and a united front are analyzed. The strategy achieves the ideal stable conditions. We define the relevant definition of a smart community and discuss the purpose and significance of the research, especially the importance and necessity of the construction of the smart community. Based on the current situation of the construction of smart communities, we conduct specific research, discuss the deficiencies and shortcomings in the current construction of smart communities, and find out the causes of these problems. Finally, based on learning from the relevant work experience, corresponding improvement measures are proposed for the existing problems from the united front, top-level design, social participation, platform construction, and talent training.
\end{abstract}

\section{Introduction}

As a standpoint for the development of modern society, a smart city is also an important part of modern society. With the development of the Internet in recent years, there has been a lot of room for development in community construction innovation, especially in the construction of smart communities, ecological construction for the elderly, and community grid construction $[1,2]$. The smart community mainly has the following factors. The first is to make full use of modern science and technology; the second is to achieve the integration of resources; the third is to improve the comprehensive level of social governance; the fourth is to enable the modernization and facilitation of residents' lives [3]. So, in this sense, smart communities are a relatively new type of new concept of social governance. Building an intelligent community can not only improve the overall construction level of the community, but also reduce the cost of social governance and maximize the improvement of residents' living services with minimal investment so as to better build a multilevel intelligent social service system $[4,5]$. Driven by new social governance development requirements and a new round of technological and industrial revolution, smart communities will become an important way to innovate community governance, improve community services, and meet the needs of people's good lives. Smart communities rely on advanced technology, information technology, and infrastructure to effectively integrate the needs of the community's property services, convenience services, government affairs, medical treatment, communication, and communication in an intelligent information system to provide community residents with more convenience and comfortable, efficient, and safe living environment, so as to realize people's daily life and services in an 
intelligent and convenient way. The development of a smart community is not only the result of the continuous maturity, development, innovation, and change of the community, but also the extension of intelligence in the field of social governance [6]. The smart community service system is jointly constructed by the government and the social forces under its leadership [7]. It relies on advanced information technology and infrastructure in the smart community to meet the diverse and multilevel needs of community residents [8]. The goal is to live and innovate the community governance model, to provide community residents with various community service systems and operating mechanisms.

Niaros et al. [9] have proposed a multidimensional, multilevel study on the construction of smart communities. The research content includes support at the government level, socioeconomic needs, the dimension of the construction environment, and the level of interconnected transportation. Aiming at the dimensions of individual needs, intelligent community management, and family-level dimensions, American administrative scientists Li et al. [10] and Ted Krivý [11] proposed that public services are not necessarily fully provided or directly provided by the government. The government provides this function of public services. A variety of other more efficient ways of providing services can be sought by community workers within the community [12]. Raven et al. [13] pointed out that nonprofit organizations should provide community services as the main body, and the role of the government is mainly to advocate and support. Verrest and Pfeffer [14] believe that the government, market, community, and other entities should complement each other and establish a multicenter supply model. Community services should not be a single or one-to-one supply model, emphasizing the diversity of supply [15]. Barns et al. [16] believe that the smart community is an autonomous system that can be thoroughly perceived and interconnected by relying on advanced scientific and technological information technologies such as the Internet of Things and cloud computing. This system has many functions such as community home detection, emergency alarm, and nursing services [17]. Eckhoff and Wagner [18] have used the perspective of distance learning to build a model of smart community network learning, which includes the three dimensions of smart community development, knowledge innovation, and coaching and learning support, and explain the connotation of smart community from a content of smart community. Sandulli et al. [19] believe that a smart community is a kind of converged network built in the context of the Internet of Things. The structure of a smart community is a network architecture, which is malleable and inclusive [20]. Kumar et al. [21] believe that smart communities are different from traditional communities. They are provided for the residents of the community. They are a united front and are efficient, healthy, safe, low-carbon, energy-saving, and environmentally friendly living environment and methods. The construction of smart communities should adhere to sustainable development. Sookhak et al. [22] considered that smart communities are key construction subprojects of smart cities and analyzed the connotation of smart communities from the perspective of smart cities, as a component of smart city construction. Kitchin [23] believes that a smart community is a community security network integration system. The construction and development of the community should first consider the issue of community security [24]. Using wireless sensor technology, a sensor network can be built, and community security can be placed in it.

The research on smart communities has covered many aspects including the basic concept connotation, information technology support and standards, construction status issues and countermeasures, and smart community evaluation. The theoretical framework of the smart community has been gradually improved, but the service system of the smart community is the core component of the smart community. Its research is still in the exploratory stage, and there is less research in this area. Concentrating on the research of a single part of the service content such as old-age care and medical care, the research is relatively scattered, there are many deficiencies, and there is a lack of systematic analysis and design. If smart communities rely solely on technology and do not cooperate with the appropriate service system, they will restrict the development of smart communities, hinder the intelligent development of social governance, and build a process of coconstruction and shared governance. The selection of this paper is mainly based on the intelligent management of the community as the research target. The theoretical concept of smart city construction under dynamic games is combined with the specific construction practice of the smart community to analyze the problems and shortcomings of the current status. The research in this paper has both a certain theoretical significance and corresponding practical value. On the one hand, it can enrich the united front related theories of social services and community governance, and on the other hand, it can provide some data theory and practical experience to the latecomers studying smart communities.

\section{Study on Community Governance of Smart City Construction in Dynamic Game}

2.1. Analysis of the Game Relationship between Smart City Construction and Community Governance. Smart city planning and construction groups, business groups, and social public groups are the most important stakeholders in urban planning and construction. The three groups' decision-making interaction directly affects the process of local urban planning and construction. Smart city planning and construction groups make decisions intending to maximize the public interest in the region. They are the leaders, guides, and maintainers of urban planning and construction. They regulate the production and living behavior of enterprise groups through effective policy regulations and incentives. Decision making with the goal of maximizing benefits is the main body and promoter of green production and determines its production strategy according to market preferences and government policies; social public groups make decisions with the goal of maximizing personal interests and are the supervisors and markets of society of consumers, 
determining their decision-making behaviors based on the utility of the goods to themselves and the individual gains and losses in social construction. Due to different interest preferences among the three major groups, different strategies will be selected, which will affect the effectiveness of urban planning and construction. Therefore, by establishing an interactive game model among the three main bodies, a united front is formed. Using evolutionary game method to analyze the strategy evolution process and trend of each group has positive significance for the optimal mechanism design and system construction of urban planning and construction. This draws an expanded game model for participation in smart city construction (Figure 1).

The smart community service system is a system architecture and operating mechanism for smart communities to implement community governance and services. It aims to provide community residents with efficient, convenient, and intelligent services through information technology and facilities. The smart community service system is supported by technology and information such as the Internet of Things, information technology, and urban big data. It is the responsibility of the government. Through various methods such as government purchase, it integrates the multiresources of community neighbourhood committees, enterprises, social organizations, and community residents to jointly achieve and provide diverse and multilevel services such as government services, life services, elderly services, united fronts, medical services, volunteer services, and property services, integrate the realization of various services, and use information technology and infrastructure to create online intelligence. The service application platform and offline intelligent service management platform provide various types of quality services to community residents through two major platforms. Community residents can participate in community governance through online smart service application platforms and offline smart service management platforms, or by directing prosecutions and expressing opinions and satisfaction with service subjects. The operation mode of the community service system is shown in Figure 2.

To meet the needs of residents is the fundamental purpose. Under the new public service theoretical framework that advocates "service instead of helm" and "pursuit of public interest," the construction of a smart community service system should take service as the king and pursue the public interests of community residents as the foundation. It is necessary to accurately grasp community residents demand for various services, such as public service government affairs, social security, employment services, family planning and other services, convenient water and electricity provision, communications, pensions, medical care, housekeeping, shopping, and other services. To understand the degree of community residents' demand for various services, supply methods, and efficiency of service delivery, keep up with the times, dynamically update, and continuously optimize the service supply methods to improve service levels. The construction of a smart community service system should focus on the needs of residents, build high-rise houses, formulate top-level designs, and arrange service methods and approaches.

\subsection{Experiment Apparatus}

Hypothesis 1. There are two important groups in the process of urban planning and construction: (1) Group A is the department responsible for urban planning and construction; (2) Group B is a relevant functional department that belongs to Group $\mathrm{A}$ and involves urban planning and construction. They each have two decision-making schemes. Group A can choose to actively implement the country's construction requirements for urban planning (Strategy 1) or passively implement this requirement (Strategy 2), while Group B can choose to support Group A work (Strategy 1) or not to support Group A work (strategy 2). Individuals in both groups have limited rationality and will adopt imitation strategies to adjust their game strategies based on the choices of others in the group.

Hypothesis 2. The cost of Group A's active execution is $C_{1}$, which is expressed as the human and financial input for execution; at the same time, it will receive the opportunity benefit $I_{1}$, which is expressed by the superior government's reward and the government's reputation improvement. At this time, if Group B supports, they will get auxiliary gains, which shows that they have saved manpower and material resources. When Group A performs negatively, it will be punished by the higher government for future financial penalties, which will be recorded as a fine $L_{1}$.

Hypothesis 3. The cost of Group B's support for construction is $C_{2}$, which is also manifested in human and financial input. At this time, when Group A is actively performing, it will also receive opportunity income $I_{2}$, which is shown as an increase in reputation and political performance. When it is not supported, if Group A insists on actively implementing the financial penalty $L_{2}$ for Group B, it will show the reduction of financial support for the next year.

Hypothesis 4. In the process of comprehensive urban planning, the proportion of Group A which chooses to actively execute the strategy is represented by $x(x \in[0,1])$, and the proportion of people who choose to execute the passive strategy is $(1-\mathrm{x})$. The proportion choosing to support the construction strategy is represented by $y(y \in[0,1])$, and the proportion choosing not to support the construction strategy is $(1-y)$. Table 1 shows the model parameters.

Based on the above assumptions, list the game matrix between Groups A and B as shown in Table 2.

$$
E_{x 1}=y\left(I_{1}-C_{1}+A_{1}\right)+(1-y)\left(I_{1}-C_{1}+L_{2}\right) .
$$

The expected return from negative construction can be expressed as

$$
E_{x 2}=y\left(-L_{1}\right)+(1-y)\left(-L_{1}\right) .
$$

The average expected return can be expressed as 


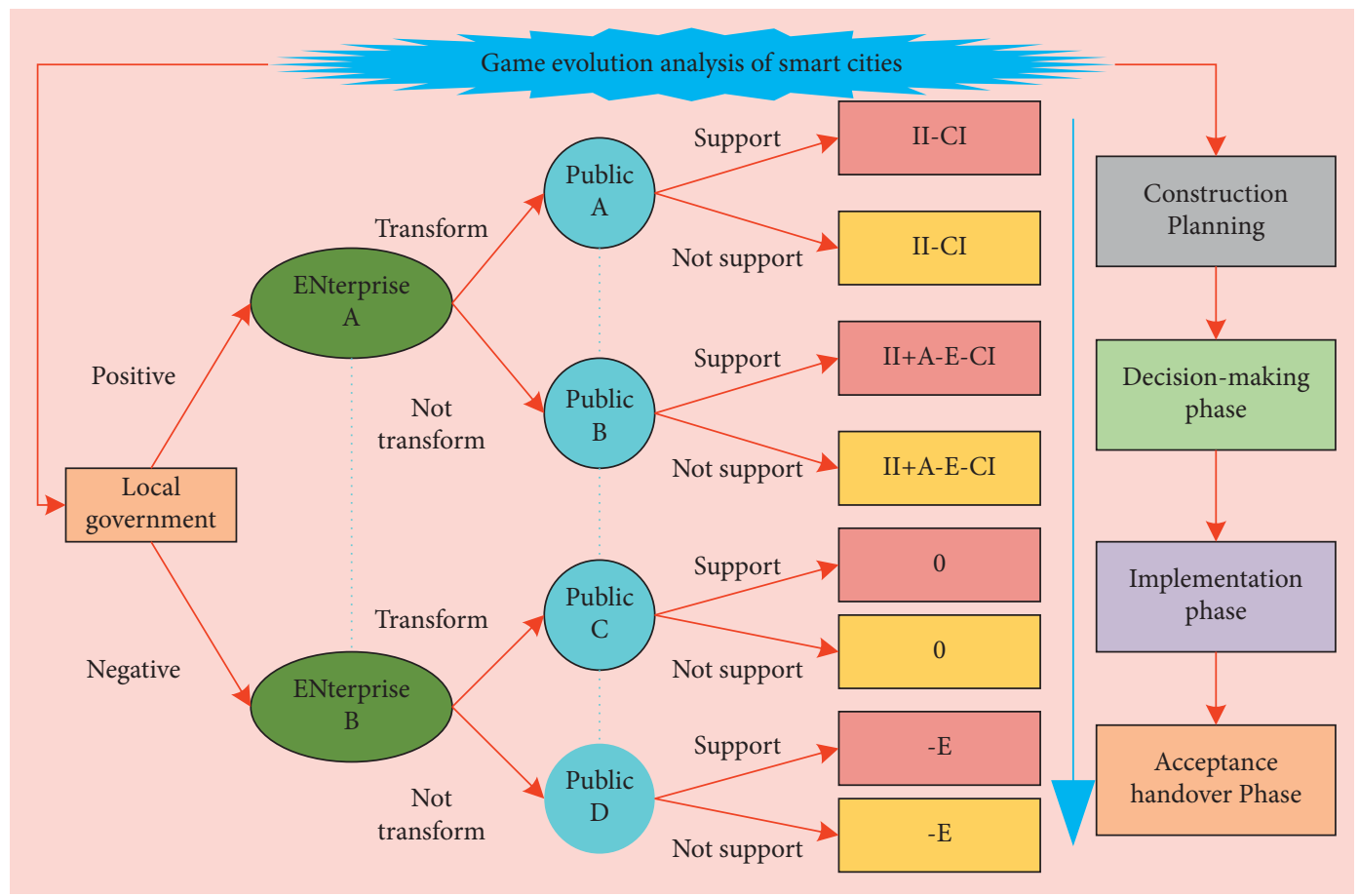

FIGURE 1: Gaming tree of revenue of smart city construction.

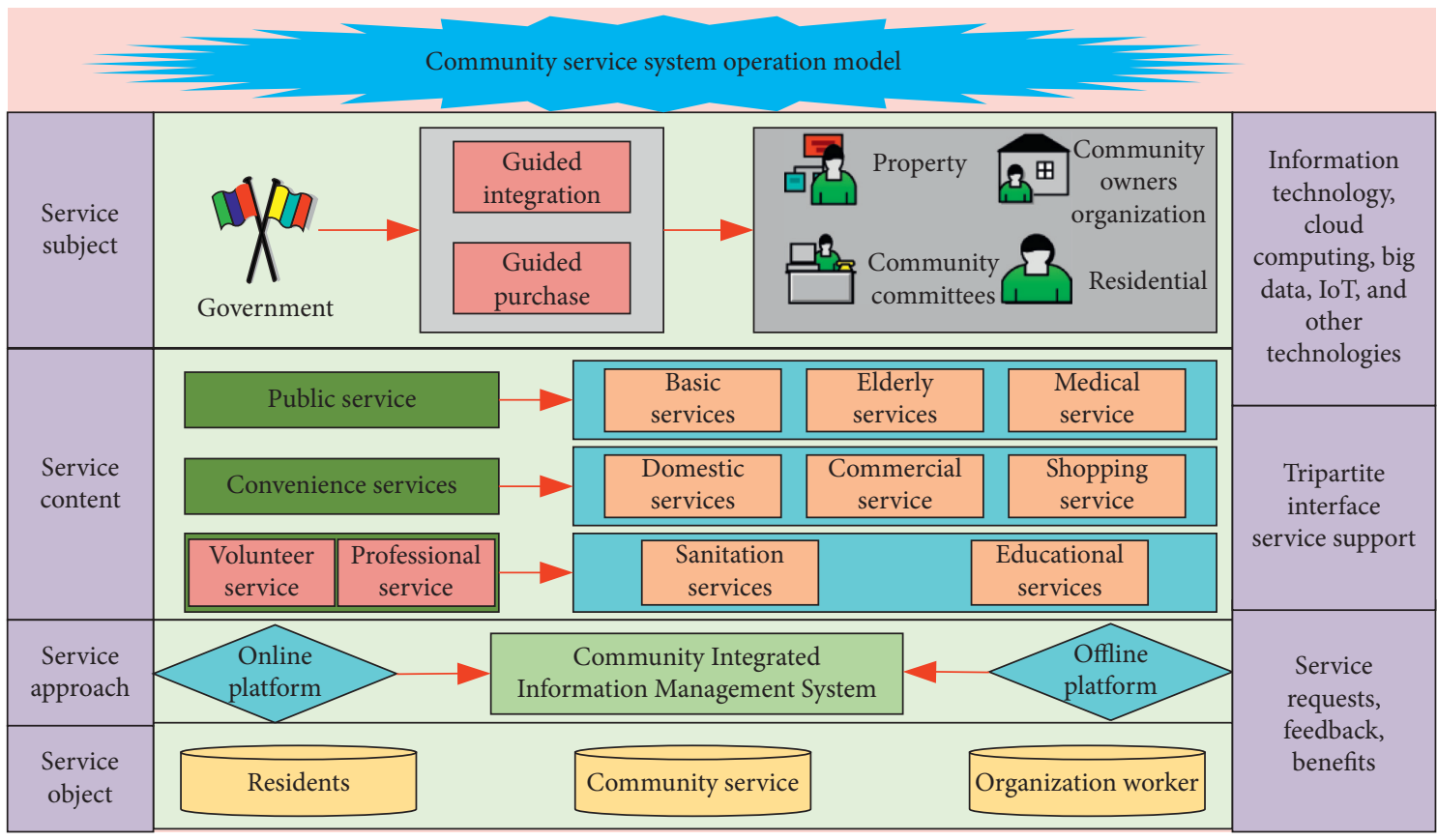

FIgURE 2: The composition of community service system and its operation mode. 
TABLe 1: Partial patient information.

\begin{tabular}{lccc}
\hline Serial number & Symbol & Symbolic meaning & Involved groups \\
\hline 1 & $C_{1}$ & Execution cost of department A & A \\
2 & $I_{1}$ & Opportunity gains performed by department A & A \\
3 & $A_{1}$ & Auxiliary gain & A, B \\
4 & $L_{1}$ & Fines imposed by department on department A & B \\
5 & $C_{2}$ & Execution cost of department B & B \\
6 & $I_{2}$ & Opportunity gains performed by department B & A, B \\
7 & $L_{2}$ & Department A's penalties for department B & A \\
8 & $x$ & Department A group choosing to actively implement the strategy & B \\
9 & $y$ & Department B group choosing support strategy & \\
\hline
\end{tabular}

TABLe 2: Game matrix.

\begin{tabular}{lcc}
\hline Department & Support (y) & Not supported (1-y) \\
\hline Active execution $(x)$ & $-C_{1}+\mathrm{I}_{1}+A_{1},-C_{2}+\mathrm{I}_{2}$ & $-C_{1}+\mathrm{I}_{1}+L_{2},-L_{2}$ \\
Passive execution $(1-x)$ & $-L_{1},-\mathrm{C}_{2}$ & $-L_{1}, 0.0$ \\
\hline
\end{tabular}

Write down the expected return from Group A's active execution as.

$$
\begin{aligned}
\overline{E_{x}} & =x E_{x 1}+(1-x) E_{x 2} \\
& =x\left[y\left(I_{1}-C_{1}+A_{1}\right)+(1-y)\left(I_{1}-C_{1}+L_{2}\right)\right]+(1-x)\left[y\left(-L_{1}\right)+(1-y)\left(-L_{1}\right)\right] .
\end{aligned}
$$

Write the replicated dynamic equation of Group A:

$$
G(x)=\frac{\mathrm{d} x}{\mathrm{~d} t}=x\left(E_{x 1}-\overline{E_{x}}\right)=x(1-x)\left(I_{1}-C_{1}+L_{2}+y A_{1}-y L_{2}+L_{1}\right)
$$

It is not difficult to find that the independent variables in this equation only exist in the part of $x(1-x)$, so let the part that has nothing to do with $x\left(I_{1}-C_{1}+L_{2}+\mathrm{yA}_{1}-\mathrm{yA}_{2}+L_{1}\right)$ be expressed by a formula. Therefore, the expected return of Group B's choice of transformation and upgrading strategy can be expressed as

$$
E_{y 1}=x\left(I_{2}-C_{2}\right)+(1-x)\left(-C_{2}\right) .
$$

The expected benefits of choosing a nontransformation upgrade strategy can be expressed as

$$
E_{y 2}=x\left(-L_{2}\right) \text {. }
$$

The average expected return can be expressed as

$$
\begin{aligned}
\overline{E_{y}} & =y E_{y 1}+(1-y) E_{y 2} \\
& =y\left[x\left(I_{2}-C_{2}\right)+(1-x)\left(-C_{2}\right)\right]+(1-y)\left[x\left(-L_{2}\right)\right] .
\end{aligned}
$$

Write the replicated dynamic equation of Group B:

$$
G(y)=\frac{\mathrm{d} y}{\mathrm{~d} t}=y\left(E_{y 1}-\overline{E_{y}}\right)=y(1-y)\left[x I_{2}-C_{2}+x L_{2}\right] .
$$

By analyzing the evolutionary system composed of dynamic equations $G(x)$ and $G(y)$, we analyze the evolutionary stability strategy (ESS) of Group A and Group B, and the equilibrium point stability of the system can be determined by referring to the local stability analysis method of the Jacobi matrix.

The Jacobi matrix of the game is listed as

$$
\text { Jacobi }=\left(\begin{array}{cc}
(1-2 x) \alpha & x(1-x)\left(A_{1}-L_{2}\right) \\
y(1-y)\left(I_{2}+L_{2}\right) & (1-2 y) \beta
\end{array}\right) \text {. }
$$

Determinant of J:

$$
\text { Det J }=(1-2 x)\left(I_{1}-C_{1}+L_{2}+y R_{1}-y L_{2}+L_{1}\right)(1-2 y)\left[x I_{2}-C_{2}+x L_{2}\right]-y(1-y)\left(I_{2}+L_{2}\right) x(1-x)\left(R_{1}-L_{2}\right) \text {. }
$$


Traces of J:

$$
\operatorname{Tr} J=(1-2 x)\left(I_{1}-C_{1}+L_{2}+y R_{1}-y L_{2}+L_{1}\right)+(1-2 y)\left[x I_{2}-C_{2}+x L_{2}\right] .
$$

\section{Result Analysis}

3.1. Analysis of Evolutionary Stability in Dynamic Games. To more intuitively express the evolution process of emergency decision information sharing behavior, this paper uses MATLAB simulation tools to simulate conclusions 1,2 , and 3 at different initial points under different circumstances and evolve to the aggressive strategy. In Figure 3, the horizontal axis represents time $(\mathrm{t})$ and the vertical axis represents the proportion of active strategies selected in smart city planning and construction $(x)$ or number to govern $(y)$. That is, when the value of the parameters meets the above conditions, the evolutionary stabilization strategy of smart city planning and construction is active integration. For the convenience of analysis, under the conditions that the above evolutionary stability strategy is satisfied, it is assumed that the parameter value is $E=3$; $\alpha=0.4 ; \beta_{1}=0.8 ; \beta_{2}=0.2 ; P=0.5 ; L=0.6 ; C_{1}=1.5$.

It can be seen from the evolution process in Figure 3 that no matter what the initial proportion of the active integration strategy for smart city planning and construction is, the final evolutionary stability strategy ratio converges to 1, that is, the active integration strategy. It can be seen that the smaller the initial proportion of smart city planning and construction, the faster the convergence rate, and all the curves will not cross before reaching stability. The cost of actively integrating information in smart city planning and construction is less than the benefit of information value brought about by the improvement of the ability of community governance to actively share information and transform it. Regardless of the initial proportion of community management's choice of active sharing strategy, the final evolutionary stable strategy ratio converges to 1 , that is, the active sharing strategy. It can be seen that the smaller the initial proportion of community governance, the faster the convergence rate, and all the curves will not cross before reaching stability. At this time, the risk brought by enterprises to reduce the density of information is greater than the net income of active sharing and less than the sum of the net income of active sharing, the reward of active sharing, and the penalty.

The evolutionary stability strategy for smart city planning and construction is 1 , and the evolutionary stability strategy for smart city planning and construction is 0 . The evolution diagram is shown in Figure 4.

It can be seen from Figure 4 that when the initial proportion $\mathrm{x} 0$ of the smart city planning and construction cluster is greater than 0.72 , that is, 0.8 and 0.9 in the figure, the final evolutionary stability strategy of the smart city planning and construction cluster is 1 (active integration). When the initial ratio $\mathrm{x} 0$ of the planning and construction cluster is less than 0.72 , that is, $0.2,0.4$, and 0.6 in the figure, the final evolutionary stabilization strategy for the planning and construction cluster of the smart city is 0 (negative integration). In the same way, under the abovementioned prerequisites, the evolutionary stability strategy of community governance clusters under different initial proportion conditions.

When the cost of integrating information in the smart city planning and construction department is low enough, the strategy of smart city planning and construction has nothing to do with the choice of community governance strategies. Active integration of information is an evolutionary and stable strategy for smart city planning and construction, that is, the difference between the benefits of actively integrating information and the cost of actively sharing information. When it is large enough, the strategy of community governance has nothing to do with the strategic choice of smart city planning and construction. Active sharing of information is an evolutionary and stable strategy for community governance. In the planning and construction process of smart city, we need to plan and construct information, integrate cost, share information of community governance, and improve the ability of information conversion, improving information hiding coefficients, and actively integrating information conversion capabilities and smart city planning and construction, government incentives both the level and the active sharing of profits by enterprises can promote the evolution of smart city planning and community governance to a dualpositive strategy (active integration, active sharing), forming a united front.

3.2. Analysis of Dynamic Game Decision Methods. The effectiveness of the corresponding emergency plan for different levels of community governance $E$ : the prior probability is $\mathrm{P}(i)$ of the four levels of community governance in the first stage, and when the actual level of the nuclear accident is $i$, but the joint meeting judges the level of accident, the conditional probability is $\mathrm{P}(\mathrm{ij})$. The above data in the actual nuclear emergency are discussed and decided by the emergency decision-making group, that is, the joint meeting on countermeasures for atomic disasters, relying on the judgment of experts in nuclear emergency decisionmaking. The analysis of this example mainly explores the operability and theoretical feasibility of the model. To facilitate the analysis, the above three types of fuzzy data will be assumed. It is assumed that the corresponding scheme corresponds to the utility $E$ of different levels of community governance, as shown in Figure 5.

It is also assumed that when the actual level of the nuclear accident is $i$, the conditional probability that the 


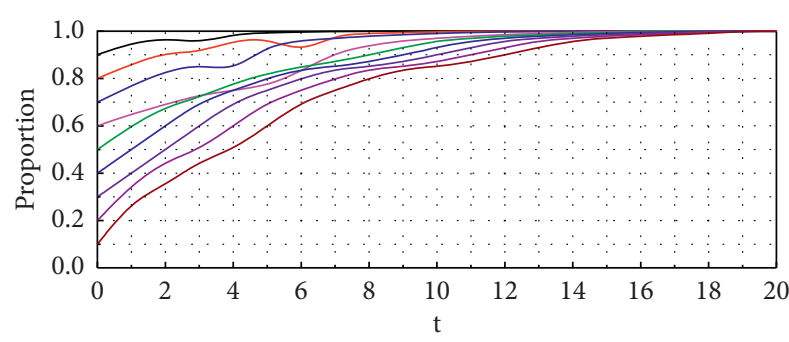

(a)

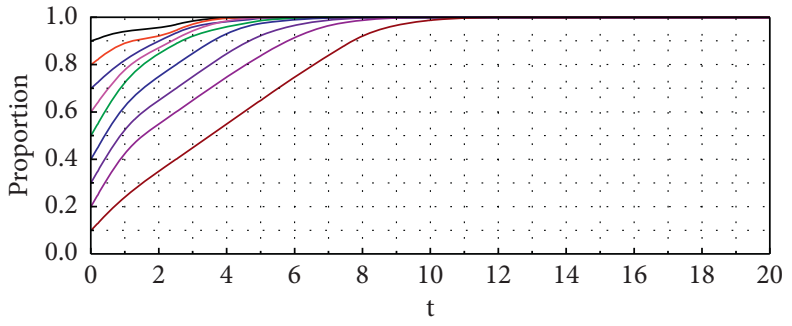

(b)

Figure 3: (a) Proportion of evolution strategy. (b) Proportion of evolution strategy shared by community governance.

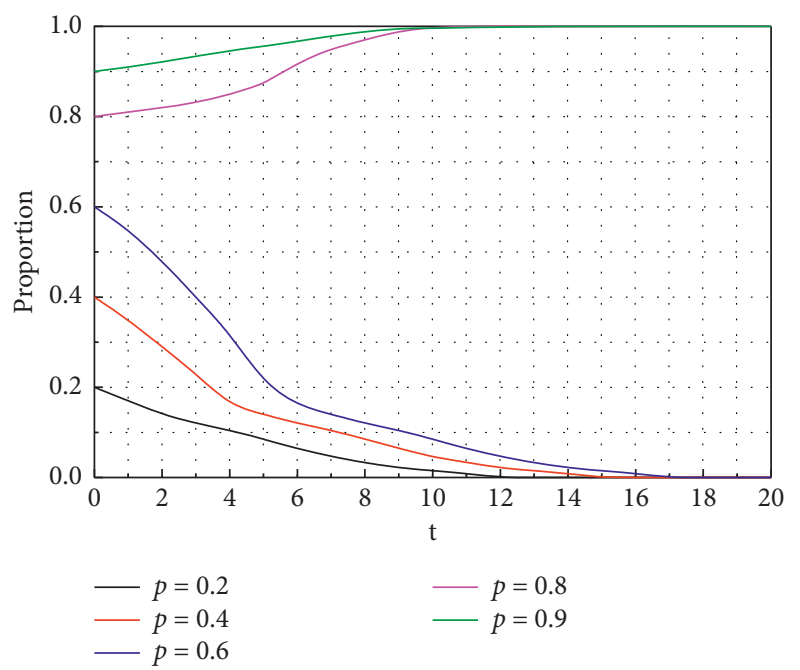

FIGURE 4: Schematic diagram of the evolution of smart city planning and construction.

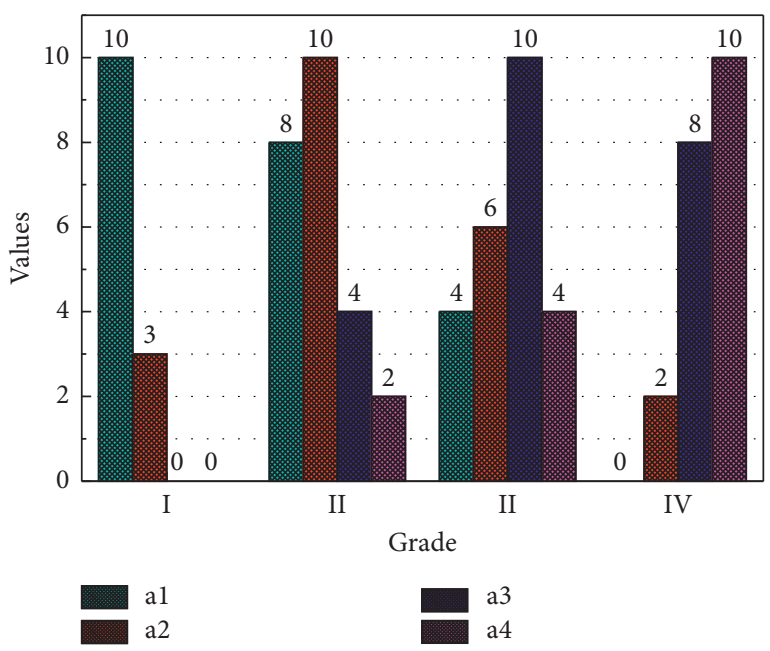

Figure 5: Optional emergency plan effect.

joint meeting judges that the level of the accident is $j$ is $\mathrm{P}(i j)$, and the value of the conditional probability is shown in Figure 6.

According to the calculation steps, all posterior probabilities of the four levels of nuclear accidents can be calculated, as shown in Figure 7.

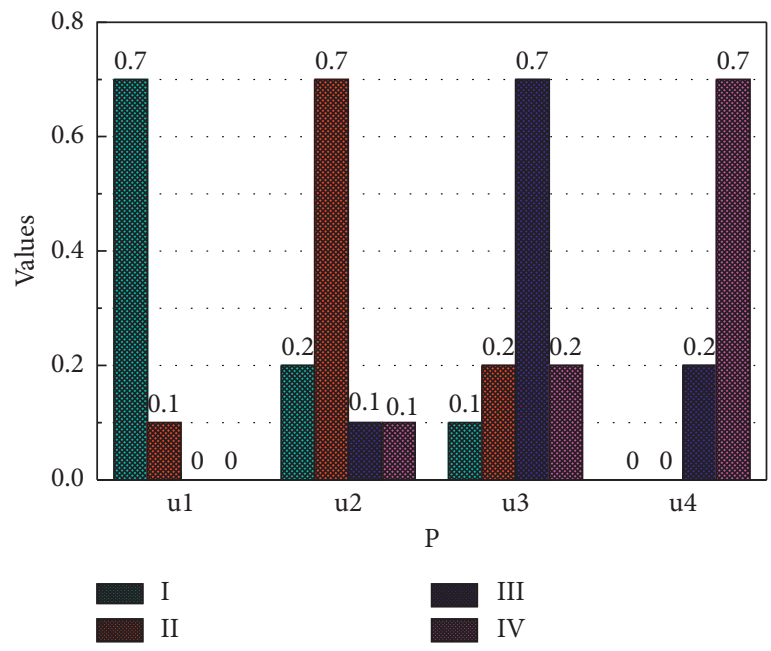

FIgURE 6: The value of conditional probability $\mathrm{P}(i j)$ in the first stage.

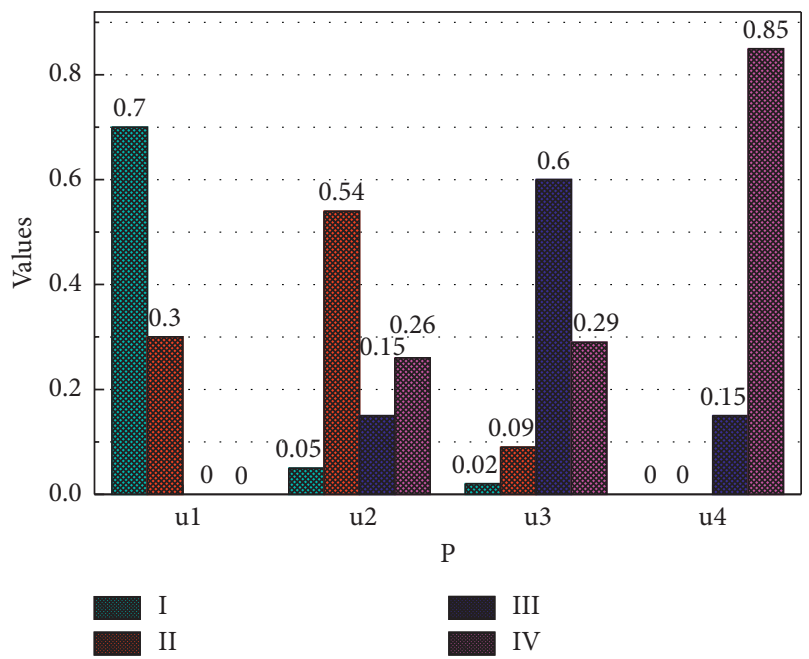

FIgURE 7: The value of the posterior probability $\mathrm{P}(i j)$ in the first stage.

3.3. Dynamic Game Optimization Analysis. The effect of the user's strategy level on the expected equilibrium benefits of community governance is mainly studied through numerical simulations. In order to control the impact of the data transmission rate ratio on the experiment, the data transmission rate ratio in the experiment is fixed at 0.7. 


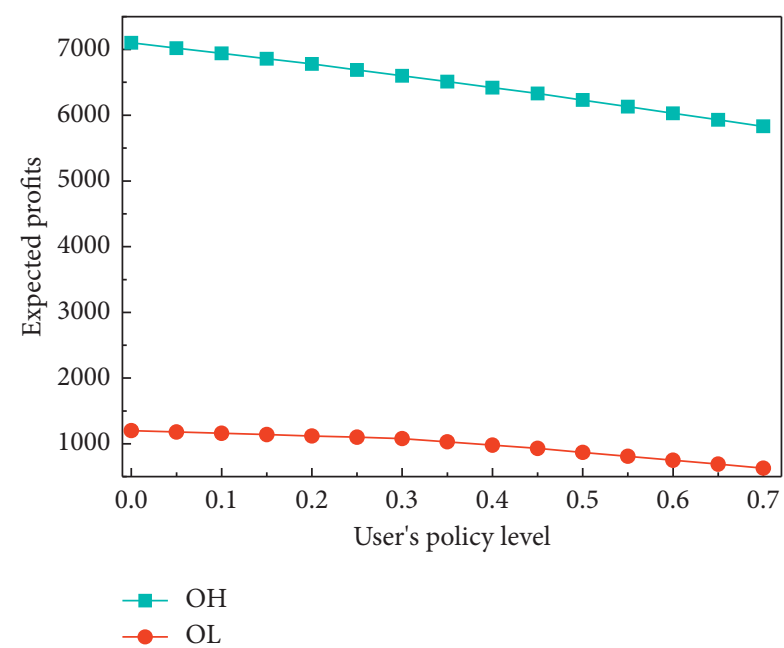

FIGURE 8: Impact of user's strategy level on expected equilibrium benefits of community governance.

The abscissa of Figure 8 represents the user's strategy level, and the ordinate represents the expected total benefits of community governance. The image visually shows that the expected total benefits of community governance in both communities decrease as the user's policy level increases. This is because a higher user policy level implies that more users will choose to delay access to the edge network. Therefore, the user's strategy will reduce the expected total benefits of community governance in the competitive pricing model.

Next, compare the differences in expected equilibrium returns of community governance in the face of "irrational" users and strategic users, as shown in Figure 9. The abscissa indicates the user's strategy level, and the ordinate indicates the percentage difference in the expected equilibrium benefits of community governance from the transition from 'irrational' users to strategic users.

It can be found from the figure that the image function values are all below 0 , which verifies the previous conclusions: the user's strategic behavior will reduce the equilibrium benefits of community governance. In addition, it can be found that the higher the user's policy level, the greater the loss of community governance benefits, because strategic users will choose to delay access to the edge network, making the price elasticity of demand greater. Changing the value from 0 to 1 , we found that the simulation results are consistent with the above, so this simulation result can explain the problem.

Because the distributed dynamic optimization scheme we proposed is cooperative, each independent subsystem has its own objective function, but in the cooperative dynamic game optimization calculation, all the subsystem goals are to make the entire overall optimization performance of the system the largest. So the objective function used by each subsystem is to improve the optimization performance of the entire system and should be consistent. For the selection of the objective function, the general approach is to linearly add the objective functions of each independent subsystem, and the coefficients are determined according to the actual

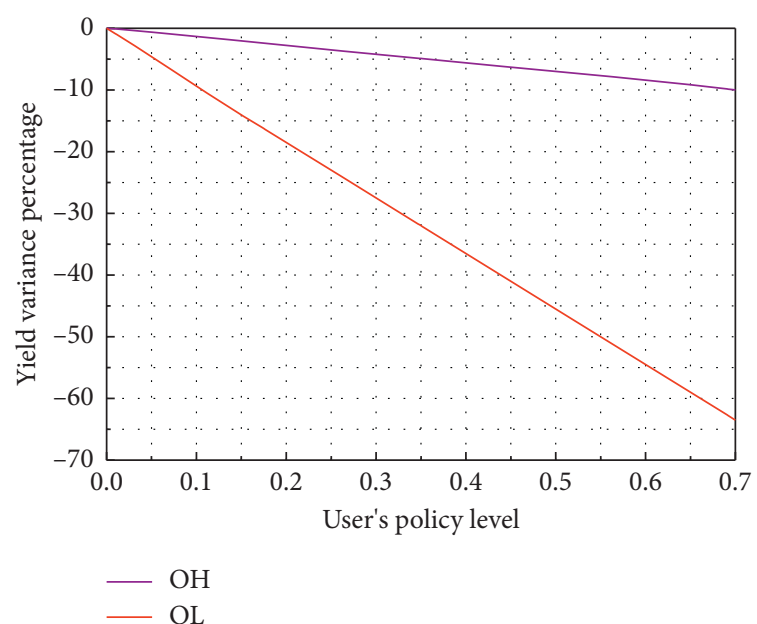

FIgURE 9: Impact of user policy levels on equilibrium.

production conditions, situation, and united front. Therefore, we integrate the above three objective functions into the overall objective function of a large system, as shown in Figure 10.

Under the RCGO dynamic optimization scheme, the iterative convergence and number of iterations of the optimization solution in each optimization cycle are shown in Figure 11. The Euclidean norm is that of the difference between the optimal controls obtained by the last two consecutive iterations in each optimization cycle. The numbers are all less than the set iteration termination tolerance $\varepsilon=0.001$. This means that, in each optimization cycle, the RCGO dynamic optimization solution can successfully converge when solving large-scale dynamic optimization problems of process networks. At the same time, the number of iterations of the optimization solution in each optimization cycle is less than the set maximum number of iterations. The results of these numerical simulations show that the RCGO dynamic optimization scheme can effectively solve large-scale dynamic optimization problems.

Next, we compare the economic performance indicators of the process network, closed-loop control performance indicators, and real-time calculation performance indicators to the advantages and disadvantages of RCO and RCGO dynamic optimization solutions. When the RCO and RCGO dynamic optimization solutions are used to solve the largescale dynamic optimization problem of the process network, the economic benefit indicators of the process network are 1.3541 and 0.9160 , respectively, and the closed-loop control performance indicators of the process network during the 100-s online optimization operation are as shown in Figure 12. From the results of the above numerical simulations, it can be seen that when the RCO scheme is used to solve the large-scale dynamic optimization problem of the process network, the economic benefit indicators and closed-loop control performance indicators of the process network obtained are optimal. This is because the RCO scheme simultaneously considers all the control variables in the process network when optimizing the solution, so the results of the optimization solution under this scheme often take 


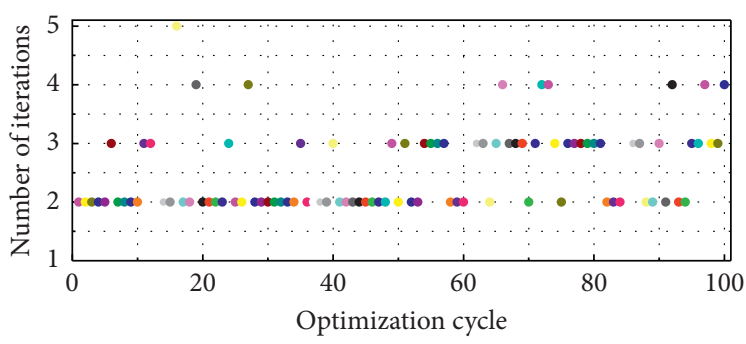

(a)

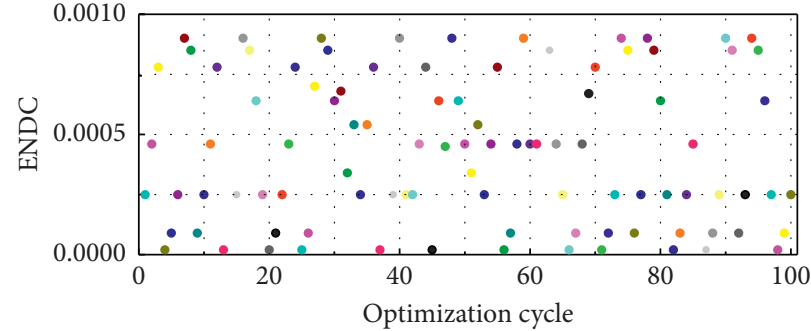

(b)

Figure 10: (a) The iterative convergence of the optimization solution. (b) The number of iterations of the optimization solution.

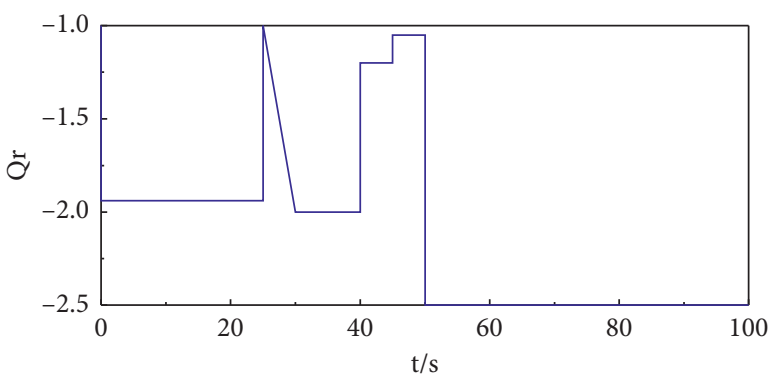

(a)

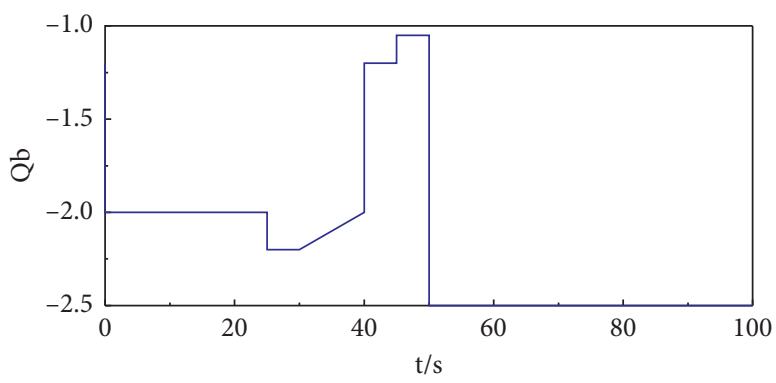

(c)

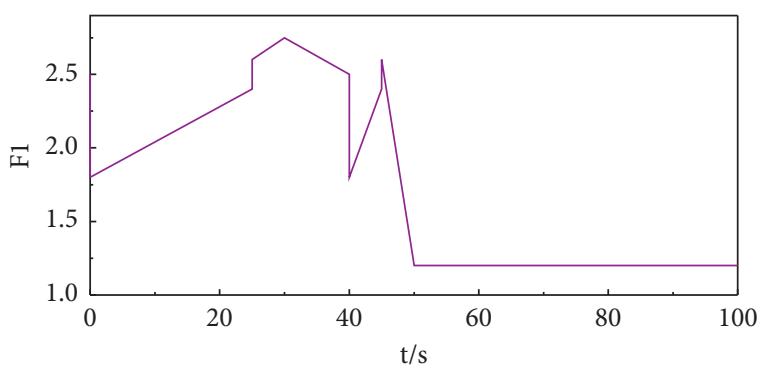

(e)

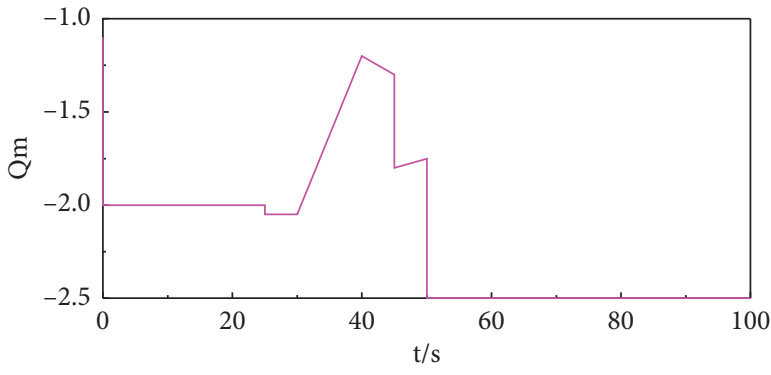

(b)

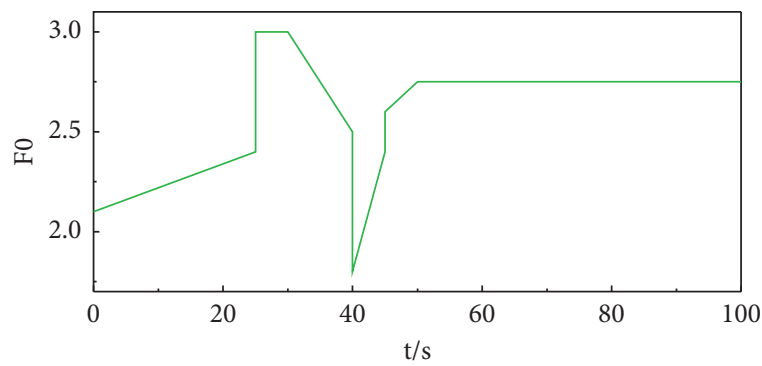

(d)

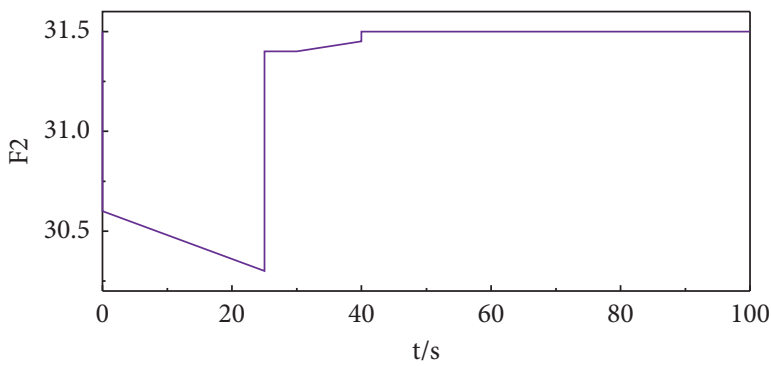

(f)

Figure 11: Sequence diagram of each control variable of the system under the RCO scheme.

into account the global optimality of the dynamic optimization problem.

When using the RCGO scheme, the scheme considers not only the overall optimization of the process network but also the optimality of each subsystem. This will cause the global optimality of the process network dynamic optimization problem to be often not guaranteed. In other words, the quality of the economic benefit index and the closed-loop control performance index of the process network is the result of weighing the optimality of the subsystem and the overall optimality of the process network. When using the RCO scheme, the average optimization calculation time in each sampling period is longer than that using the RCGO scheme. In each optimization cycle, the RCO scheme needs to solve a large-scale dynamic optimization problem. Due to the large scale and complexity, it often takes more time and cost. At the same time, the average optimization calculation time in each sampling period under this scheme will 

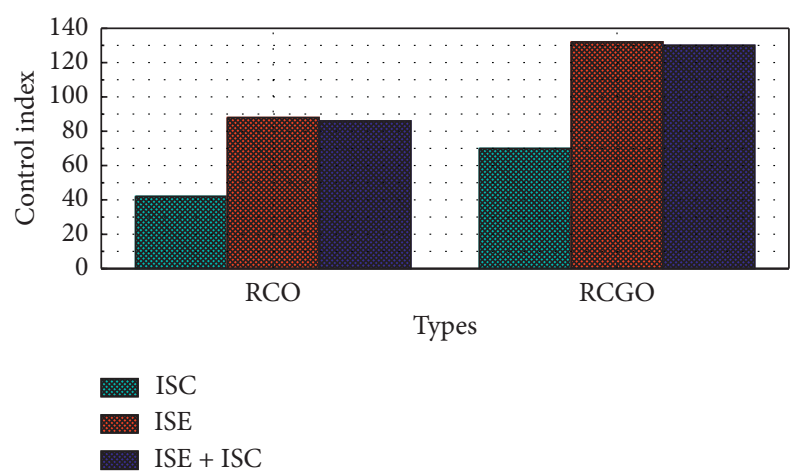

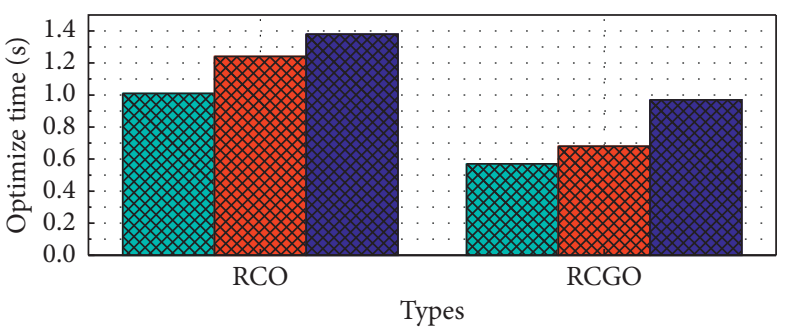

ISC
ISE
ISE + ISC

(a)

(b)

Figure 12: (a) The performance index of the closed-loop control of the process network. (b) The performance index of the real-time calculation of the process network.

exceed the sampling period length, which means that the RCO scheme will be difficult to apply to the real-time solution of the process network dynamic optimization problem. When using the RCGO solution, the system model size of the optimization solution is smaller and the solution complexity is lower than that of the RCO solution. Therefore, the solution can guarantee the real-time solution of the dynamic optimization problem of the process network. In summary, when solving complex large-scale dynamic optimization problems, the RCGO scheme has greater advantages than the traditional centralized optimization schemes in the comprehensive index consisting of system economic benefits, closed-loop control performance, united front achievement, and optimization real-time performance.

\section{Conclusion}

This article summarizes the theoretical research of smart communities, identifies and classifies the main interests of local smart cities based on previous studies, and finally determines that smart cities and community governance are the main objects of this research. Secondly, based on the assumption of bounded rationality, this study builds a dynamic game model between smart cities and community governance and finally draws the stable evolution conditions of the ideal equilibrium ESS. Guiding the behavior of smart cities mainly depends on establishing appropriate incentive mechanisms. Guiding smart cities mainly depends on setting up a reasonable reward and punishment system. The enthusiasm for stimulating public participation is to increase their recognition of smart city construction. Strengthening social supervision is beneficial for local governments to change their behaviors and fulfil their regulatory responsibilities. Then, for local governments to carry out research on the game of interests among their internal departments, the attitude of community governance is crucial. Whether it is an internal department or an external department, the degree of cooperation has a positive impact on the attitude of community governance construction. The concentration of regional environmental functions is more conducive to advancing the united front of smart cities.

\section{Data Availability}

The data used to support the findings of this study are available from the corresponding author upon request.

\section{Conflicts of Interest}

The authors declare that they have no known conflicts of interest or personal relationships that could have appeared to influence the work reported in this paper.

\section{Acknowledgments}

This work was supported by National Social Science Fund (17BSH044); Support Program for Scientific and Technological Innovation Talent in Henan Province (2018-cx-009); and Research Progress and Outcomes of the Key Incubation Programme for Philosophy and Social Science in Henan Province (2019ZDXM006).

\section{References}

[1] H. Yeh, "The effects of successful ICT-based smart city services: from citizens' perspectives," Government Information Quarterly, vol. 34, no. 3, pp. 556-565, 2017.

[2] J. Wang, C. Jiang, K. Zhang et al., "Vehicular sensing networks in a smart city: principles, technologies and applications," IEEE Wireless Communications, vol. 25, no. 1, pp. 122-132, 2017.

[3] K. Vu and K. Hartley, "Promoting smart cities in developing countries: policy insights from Vietnam," Telecommunications Policy, vol. 42, no. 10, pp. 845-859, 2018.

[4] G. V. Pereira, M. A. Macadar, E. M. Luciano, and M. G. Testa, "Delivering public value through open government data initiatives in a smart city context," Information Systems Frontiers, vol. 19, no. 2, pp. 213-229, 2017.

[5] C. Gaffney and C. Robertson, "Smarter than smart: rio de Janeiro's flawed emergence as a smart city," Journal of Urban Technology, vol. 25, no. 3, pp. 47-64, 2018.

[6] G. Viale Pereira, M. A. Cunha, T. J. Lampoltshammer, P. Parycek, and M. G. Testa, "Increasing collaboration and 
participation in smart city governance: a cross-case analysis of smart city initiatives," Information Technology for Development, vol. 23, no. 3, pp. 526-553, 2017.

[7] O. H. Gandy and S. Nemorin, "Toward a political economy of nudge: smart city variations," Information, Communication \& Society, vol. 22, no. 14, pp. 2112-2126, 2019.

[8] Y. Hayashi, Y. Fujimoto, H. Ishii et al., "Versatile modeling platform for cooperative energy management systems in smart cities," Proceedings of the IEEE, vol. 106, no. 4, pp. 594-612, 2018.

[9] V. Niaros, V. Kostakis, and W. Drechsler, "Making (in) the smart city: the emergence of makerspaces," Telematics and Informatics, vol. 34, no. 7, pp. 1143-1152, 2017.

[10] F. Li, A. Nucciarelli, S. Roden, and G. Graham, "How smart cities transform operations models: a new research agenda for operations management in the digital economy," Production Planning \& Control, vol. 27, no. 6, pp. 514-528, 2016.

[11] M. Krivý, "Towards a critique of cybernetic urbanism: the smart city and the society of control," Planning Theory, vol. 17, no. 1, pp. 8-30, 2018.

[12] A. Wiig, "The empty rhetoric of the smart city: from digital inclusion to economic promotion in Philadelphia," Urban Geography, vol. 37, no. 4, pp. 535-553, 2016.

[13] R. Raven, F. Sengers, P. Spaeth, L. Xie, A. Cheshmehzangi, and M. De Jong, "Urban experimentation and institutional arrangements," European Planning Studies, vol. 27, no. 2, pp. 258-281, 2019.

[14] H. Verrest and K. Pfeffer, "Elaborating the urbanism in smart urbanism: distilling relevant dimensions for a comprehensive analysis of Smart City approaches," Information, Communication \& Society, vol. 22, no. 9, pp. 1328-1342, 2019.

[15] I. A. T. Hashem, V. Chang, N. B. Anuar et al., "The role of big data in smart city," International Journal of Information Management, vol. 36, no. 5, pp. 748-758, 2016.

[16] S. Barns, E. Cosgrave, M. Acuto, and D. Mcneill, "Digital infrastructures and urban governance," Urban Policy and Research, vol. 35, no. 1, pp. 20-31, 2017.

[17] D. Gagliardi, L. Schina, M. L. Sarcinella, G. Mangialardi, F. Niglia, and A. Corallo, "Information and communication technologies and public participation: interactive maps and value added for citizens," Government Information Quarterly, vol. 34, no. 1, pp. 153-166, 2017.

[18] D. Eckhoff and I. Wagner, "Privacy in the smart cit$\mathrm{y}$-applications, technologies, challenges, and solutions," IEEE Communications Surveys \& Tutorials, vol. 20, no. 1, pp. 489-516, 2017.

[19] F. D. Sandulli, A. Ferraris, and S. Bresciani, "How to select the right public partner in smart city projects," R\&D Management, vol. 47, no. 4, pp. 607-619, 2017.

[20] U. Rossi, "The variegated economics and the potential politics of the smart city," Territory, Politics, Governance, vol. 4, no. 3, pp. 337-353, 2016.

[21] N. Kumar, A. V. Vasilakos, and J. J. P. C. Rodrigues, "A multitenant cloud-based DC nano grid for self-sustained smart buildings in smart cities," IEEE Communications Magazine, vol. 55, no. 3, pp. 14-21, 2017.

[22] M. Sookhak, H. Tang, Y. He et al., "Security and privacy of smart cities: a survey, research issues and challenges," IEEE Communications Surveys \& Tutorials, vol. 21, no. 2, pp. 1718-1743, 2018.

[23] R. Kitchin, "The realtimeness of smart cities," TECNOSCIENZA: Italian Journal of Science \& Technology Studies, vol. 8, no. 2, pp. 19-42, 2018.
[24] E. Okwechime, P. Duncan, and D. Edgar, "Big data and smart cities: a public sector organizational learning perspective," Information Systems and E-Business Management, vol. 16, no. 3, pp. 601-625, 2018. 